\title{
Iatrogenic False Aneurysm Following Repair of Intracranial Aneurysm
}

\author{
David W. Rowed and Beverly C. Walters
}

\begin{abstract}
False aneurysm of the intracranial arteries occurs infrequently as a complication of head injury and rarely as a consequence of other pathology. A case of false aneurysm of the supraclinoid internal carotid artery following minor intraoperative injury during clipping of a basilar-superior cerebellar aneurysm by the pterional approach is described. False aneurysm is a potential cause of recurrent intracranial hemorrhage after successful aneurysm clipping. Arterial bleeding which appears to come from the region of a branch origin should be viewed with concern even if it subsides spontaneously.
\end{abstract}

Résumé: Faux anévrisme iatrogénique après chirurgie pour anévrisme intracrânien. Un faux anévrisme des artères intracrâniennes est une complication rare d'un traumatisme crânien ou suite à une autre pathologie. Nous décrivons un cas de faux anévrisme de la portion supraclinoïde de la carotide interne suite à un traumatisme mineur pendant une chirurgie pour clipper un anévrisme de l'artère basilaire cérébelleuse supérieure par voie ptérionale. Un faux anévrisme est une cause potentielle d'hémorragie intracrânienne récidivante suite au clippage d'un anévrisme. Un saignement artériel qui semble provenir de la région d'une bifurcation est un signal d'alarme, même s'il s'arrête spontanément.

Can. J. Neurol. Sci. 1994; 21: 346-349

Traumatic aneurysms of the intracranial arteries are a well recognized entity. They have been reported following penetrating ${ }^{\prime}$ and closed head injuries, ${ }^{2-6}$ either resulting from basal ${ }^{3}$ or vault ${ }^{4}$ skull fracture or unassociated with fracture. Virtually all traumatic aneurysms are false aneurysms resulting from a small full thickness rent in the arterial wall with surrounding organizing hematoma, the aneurysmal wall being composed of fibrin early and collagen later. Some traumatic aneurysms may arise as a result of partial thickness injury to the arterial wall with the adventitia remaining intact. ${ }^{7,8}$

Almost all reported intracranial false aneurysms are traumatic. Invasion of blood vessels by metastatic carcinoma has led to false aneurysm formation, ${ }^{9,10}$ and iatrogenic false aneurysm has occurred after needle aspiration of the subdural space $^{11}$ or of cerebral abscess ${ }^{12}$ and following leukotomy. ${ }^{12}$ Arterial injuries associated with meningioma removal ${ }^{13.14}$ ethmoidal sinus surgery, ${ }^{14}$ transfrontal pituitary surgery ${ }^{15}$ and other intracranial procedures have resulted in traumatic false aneurysm.

Aneurysm formation following minor arterial trauma in the course of intracranial aneurysm clipping appears to be a rare occurrence. . $^{7.8,14.16}$

\section{Case Report}

This 35-year-old woman presented with sudden, severe generalized headache, moderate nuchal rigidity and mild obtundation following ingestion of cocaine and alcohol. Eight months previously she had experienced an episode of sudden left hemiparesis which correlated with a small lacunar infarction of the right cerebral hemisphere. After computed tomographic (CT) confirmation of blood throughout the basal cisterns, cerebral angiography disclosed a single intracranial aneurysm, measuring $8 \times 5 \mathrm{~mm}$, located at the junction of the basilar and right superior cerebellar arteries (Figure 1).

\section{First Operation}

On June 30,1992 , the aneurysm was clipped easily via a right pterional approach. ${ }^{17,18} \mathrm{~A}$ small amount of bleeding occurred intraoperatively from the internal carotid artery (ICA) in the region of the posterior communicating artery origin. This stopped readily after gentle tamponade over Surgicel (oxidized regenerated cellulose), following which the basilar aneurysm was clipped. When the Surgicel was removed prior to closure, preparatory to possible arterial suture, bleeding did not recur with normotension. Inspection of the site revealed no abnormality and the field was dry at closure.

\section{Postoperative Course}

The patient was neurologically intact postoperatively except for an incomplete right third nerve palsy which began to recover on the third day.

On the eighth postoperative day, a partial motor seizure occurred followed by postictal drowsiness and mild left hemiparesis. CT revealed a right acute subdural hematoma, 5 to $6 \mathrm{~mm}$ in thickness extending over much of the right cerebral hemisphere with midline shift to the left (Figure 2). Cerebral angiography was performed immediately and showed satisfactory clipping of the basilar aneurysm with severe vertebrobasilar vasospasm. Right carotid angiography showed a supraclinoid ICA aneurysm measuring $1 \mathrm{~cm}$ in diameter (Figure 3A, 3B) which had not been seen either on the preoperative angiogram (Figure

From the Division of Neurosurgery, Sunnybrook Health Science Centre. University of Toronto, Toronto.

RECEIVED IANUARY 10, 1994. ACCEPTED IN FINAL FORM MAY 1।. 1994

Reprint requests to: D.W. Rowed. Head, Division of Neurosurgery, Suite A 134, Sunnybrook Health Science Centre, 2075 Bayview Avenue, North York, Ontario, Canada M4N 3M5 


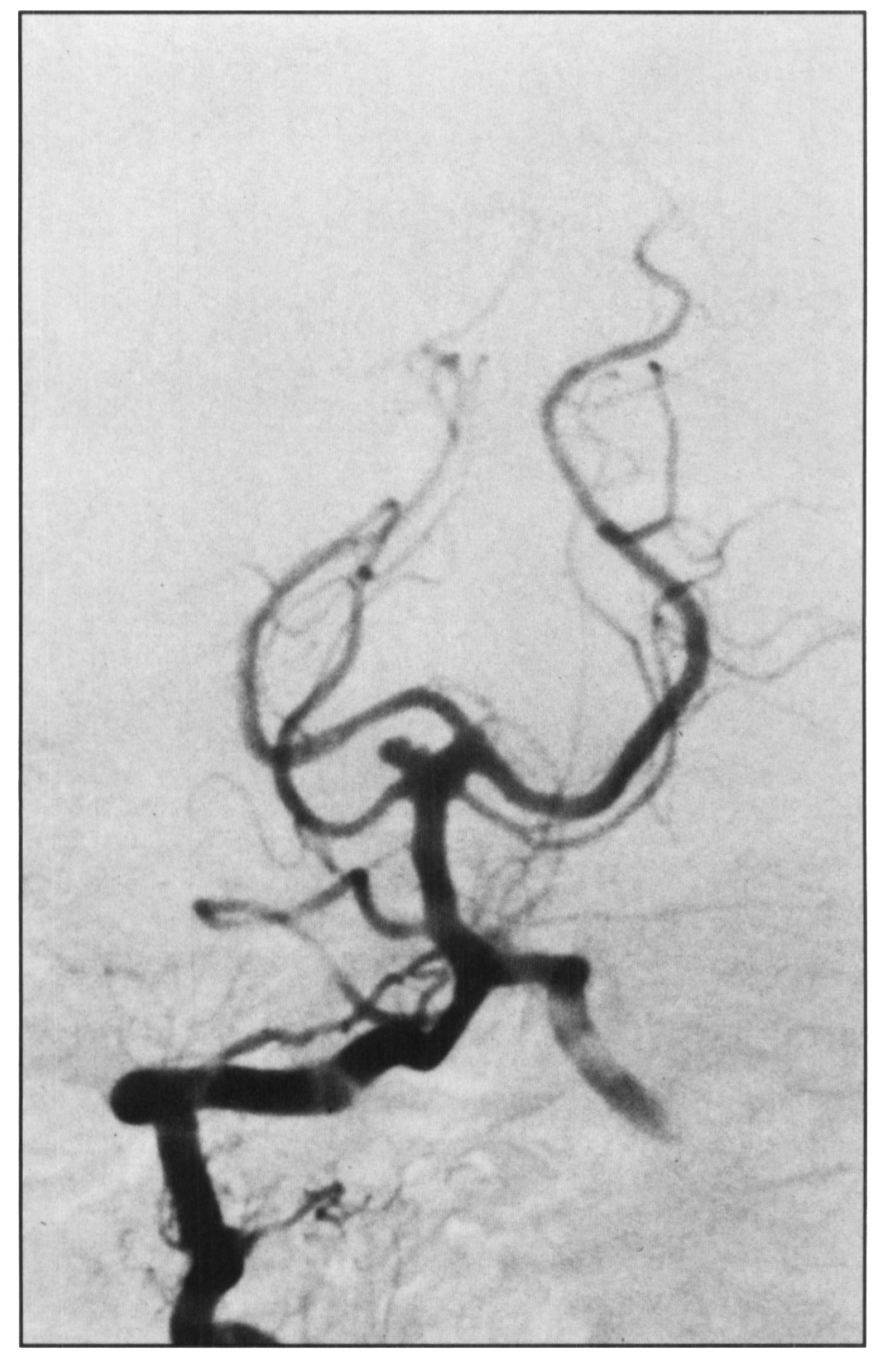

Figure 1: Right vertebral angiogram showing $8 \mathrm{~mm}$ aneurysm arising at the junction of the basilar and right superior cerebellar arteries prior to first operation.

4) or at operation. We concluded that this was a false aneurysm arising at the site of introperative bleeding from the ICA.

\section{Second Operation}

The subdural hematoma, which did not appear to be under great pressure, was evacuated. After evacuation of partially organized hematoma around the internal carotid, the dome of the false aneurysm could be seen. Temporary aneurysm clips were prepared for proximal and distal occlusion of the ICA, but before sufficient exposure could be secured in order to place them, brisk arterial bleeding occurred from the area of the false aneurysm. Angiographically the arterial jet into the false aneurysm cavity appeared to be small with prolonged filling of the sac suggesting slow flow 15 (Figure $3 \mathrm{~B}$ ) and the preoperative plan had been to repair the wall by suturing between temporary clips. Direct arterial repair proved impossible because the arterial wall opened up widely with rapid blood loss. The false aneurysm and torn arterial wall were isolated from the cerebral circulation by proximal and distal ICA occlusion. The posterior communicating artery was occluded at its proximal end, but the anterior choroidal artery origin was spared. The field was dry at closure and the appearance of the brain was unremarkable. A biopsy of the apparent wall of the aneurysm was submitted for histolog. ical examination

\section{Postoperative Course}

In the immediate postoperative period, the patient was alert with a severe left hemiplegia. CT showed infarction in the distribution of the

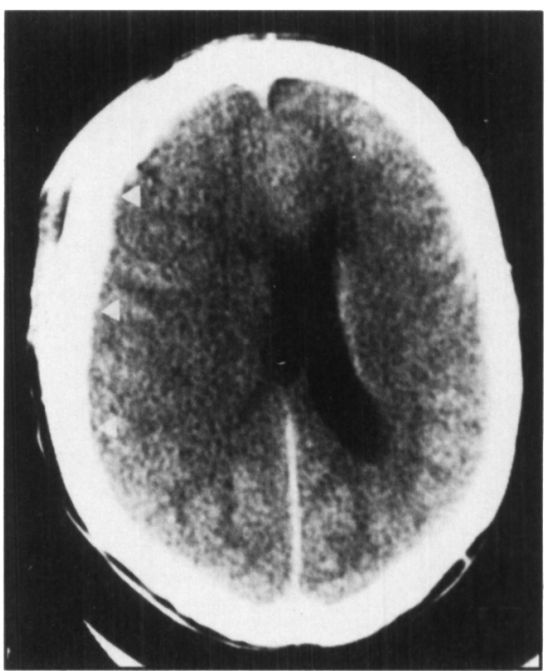

Figure 2: Acute right subdural hematoma (white arrows) with midline shift on eighth postoperative day (first operation).

right middle cerebral artery. Over the ensuing 3 weeks, the patient's clinical condition was stable, but CT showed progresssive increase in ventricular size. Ventriculoperitoneal shunt led to decrease in ventricular size associated with clinical improvement.

Since that time, the patient has shown continuing improvement, but continues to suffer from a moderately severe left hemiparesis and hemisensory deficit.

\section{Pathology}

The specimen consisted of a compacted layer of fibrin with moderate infiltration by inflammatory cells (encapsulated hematoma or false aneurysm).

\section{Discussion}

False aneurysms may arise as a consequence of full thickness disruption of the arterial wall by direct laceration or by tearing of an arterial branch. ${ }^{14}$ Confined hemorrhage with organizing hematoma forming the aneurysmal wall results. Traumatic false aneurysms of the intracranial arteries have been described in many previous reports, ${ }^{1-6.17 .19}$ resulting from closed ${ }^{2-6.15}$ or penetrating ${ }^{1,16}$ injuries, and arising from cerebral ${ }^{1-6.19}$ or meningeal ${ }^{16,20}$ vessels. False aneurysms of the cerebral vessels most often involve the anterior circulation, ${ }^{1.4-6.19}$ but may arise in the posterior circulation ${ }^{1-3.21}$ as well, and may be associated with displaced skull fracture..$^{3,4}$

True traumatic aneurysms, due to injury to the internal elastic lamina and media, leaving the adventitia intact, have been demonstrated experimentally, ${ }^{22}$ and may occur clinically. $4.7,8.11,16$

Though the majority of reported false intracranial aneurysms have been associated with head injury, other etiologies have occasionally been noted. False aneurysm apparently caused by injury to a cortical arterial vessel as a result of needle aspiration of subdural hematomas in an infant has been reported by Overton and Calvin. ${ }^{11}$ Lassman et al. ${ }^{12}$ reported traumatic intracranial aneurysms resulting from aspiration of a cerebral abscess and following leukotomy, and Parkinson and West ${ }^{15}$ reported a traumatic aneurysm resulting from transfrontal pituitary 


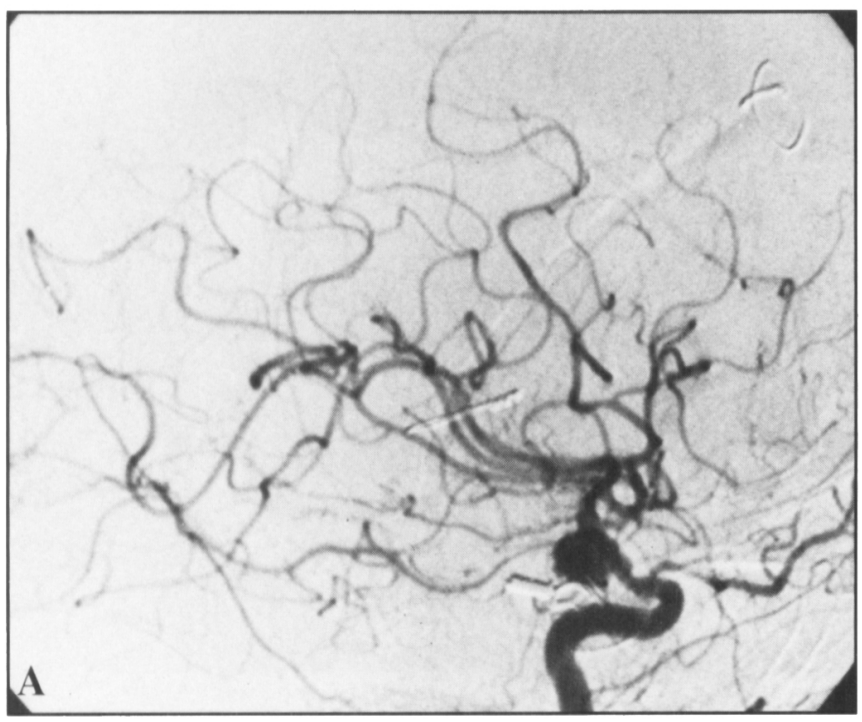

Figure 3A: Right carotid angiogram showing false aneurysm at ICAposterior commumicating arterial junction.

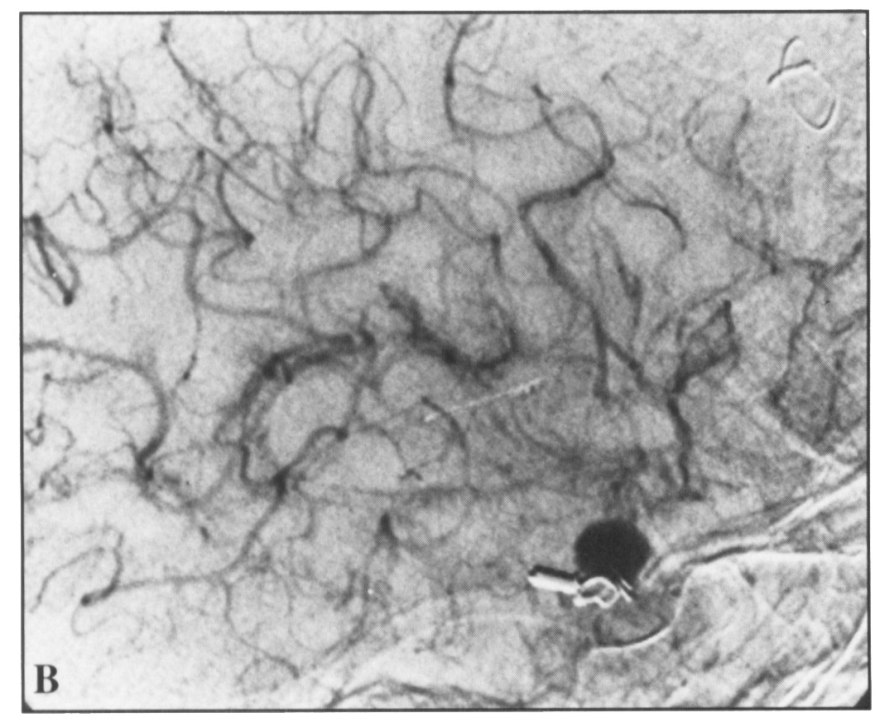

Figure 3B: Right carotid angiogram. Note slow emptying of contrast material from aneurysm sac.

surgery. Taylor ${ }^{13}$ described an apparently iatrogenic aneurysm of the MCA occurring following injury to the artery in the course of removal of a meningioma of the orbital roof. A small MCA branch had apparently been torn at its origin from the middle cerebral trunk and intraoperative bleeding had been controlled by means of hemostatic clips applied so as to spare the parent vessel. Yamaura et al. ${ }^{14}$ also reported an aneuysm arising at the carotid ophthalmic junction apparently due to traction on the ophthalmic artery in the course of removal of a tuberculum sellae meningioma.

False cerebral aneurysm resulting from apparent invasion of the wall of a cortical MCA branch by metastatic carcinoma has also been described by Reina and Seal. ${ }^{9}$ A similar case, caused by metastatic choriocarcinoma was described by Weir et al. ${ }^{10}$

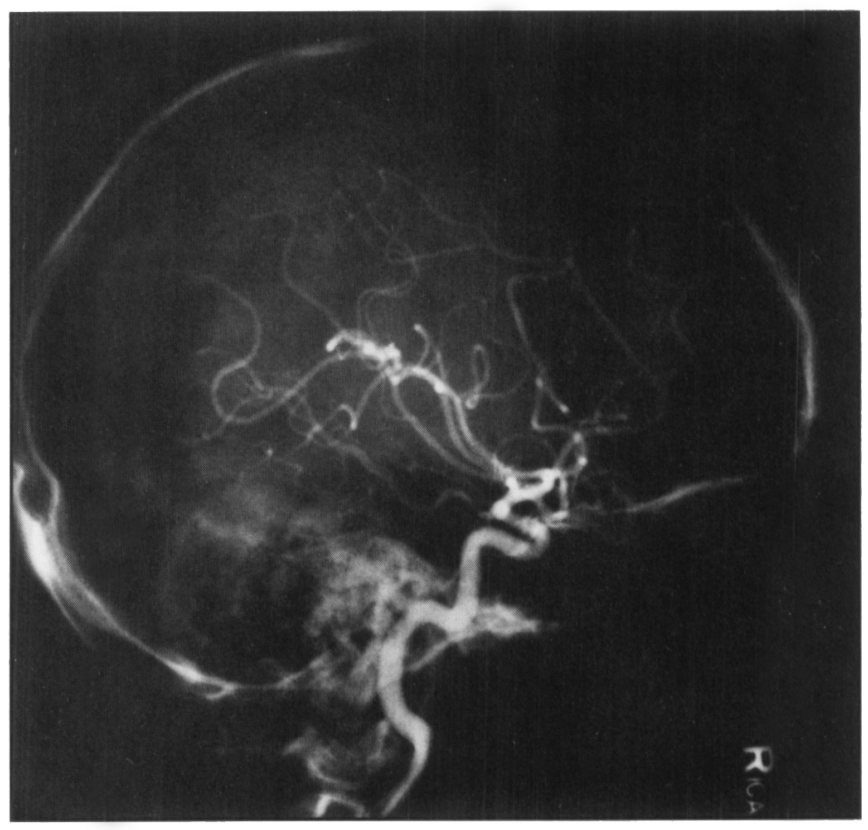

Figure 4: Right internal carotid angiogram prior to first operation. Note absence of aneurysm of supraclinoid ICA.

The tendency for this tumour to invade maternal blood vessels may increase the likelihood of false aneurysm formation.

Traumatic aneurysm following intracranial aneurysm clipping has been a rare occurrence, but has been previously reported by Raimondi et al., ${ }^{16}$ Alexander et al., ${ }^{8}$ Cosgrove et al., ${ }^{7}$ and Yamaura et al. ${ }^{14}$ Traumatic aneurysm formation typically followed weakening of the wall without initial bleeding or apparent arterial laceration..$^{7,8,16}$ In the case reported by Raimondi et al., ${ }^{16}$ the arterial wall demonstrated a small rent communicating with the false aneurysm lumen at operation, but Cosgrove et al.? described a traumatic aneurysm which bled 3 weeks after aneurysm clipping with neither arterial injury nor bleeding recognized at the original procedure. Putatively a partial thickness injury involving the internal elastic lamina and media, leaving the adventitia intact, had led to aneurysm formation. The fact that this traumatic aneurysm could be managed by clipping of a neck supports this hypothesis, though the aneurysm bled profusely during dissection. Alexander et al ${ }^{8}$ reported an unruptured traumatic ICA aneurysm apparently arising from a partial thickness wall injury from temporary application of a Mayfield clip.

Yamaura et al. ${ }^{14}$ describe traumatic false aneurysm of the ICA arising from direct laceration managed by proximal and distal temporary clipping and wrapping of the rent with Oxycel (oxidized cellulose). Intraoperative angiography showed narrowing and irregularity of the ICA but a false aneurysm subsequently developed and bled 10 days later. They also report a case in which the mechanism of the injury leading to false aneurysm formation appears to have been similar to that seen in the present case. A carotid-ophthalmic aneurysm apparently resulted from traction producing a small rent at the ophthalmic origin which subsided after tamponade over Oxycel. This mechanism is similar to the avulsion of bridging dural arteries leading to arterial subdural hematoma described by Drake. ${ }^{23}$ The 
mechanism of iatrogenic arterial injury in the present case was presumably similar to that reported by Taylor ${ }^{13}$ and Yamaura et al. ${ }^{14}$ Traction on the posterior communicating artery apparently led to a minute tear in the internal carotid arterial wall that resulted in subsequent false aneurysm formation. In the present case, however, the injury was apparently slight with spontaneous cessation of arterial bleeding after a period of gentle tamponade, and with neither recurrence of intraoperative bleeding nor apparent arterial injury on inspection prior to closure.

Clearly traction on an arterial vessel which is tethered at any point in its course is to be avoided, particularly after subarachnoid bleeding with thickened arachnoid, ${ }^{18}$ and the relative fixation of the distal end of the posterior communicating artery at its junction with the posterior cerebral artery precludes its being greatly displaced. Familiarity with this principle did not serve to prevent an iatrogenic arterial injury in the present case.

As seen in this instance, bleeding from false aneurysm usually occurs early, within days to 4 weeks of arterial injury, ${ }^{7.14}$ and mortality may be high when these lesions are missed. ${ }^{13.15}$ Parkinson and West ${ }^{15}$ reported a mortality of almost $50 \%$ with nonoperative management.

False aneurysms are fragile and usually have to be trapped and excised ${ }^{1-5.14-16}$ as in the present case. The proportion of reported traumatic aneurysms which could be managed by clipping is low varying from $11 \%$ is to $22 \% .^{14}$

Vasculitis has been confirmed at biopsy in cocaine abusers even after normal cerebral angiography. ${ }^{24}$ The present patient was a known abuser of cocaine, and had used the drug immediately prior to subarachnoid hemorrhage. Whether this circumstance had any relevance to false aneuysm development or to the extensive opening up of the ICA at operation remains speculative.

Our aim is to call attention to minor intraoperative arterial injury leading to false aneurysm formation. This is particularly important when arteries are retracted, however gently, as in the present case.

Arterial bleeding sites which subside spontaneously require very careful inspection prior to closure. This was done in the present case with failure to detect the injury which led to aneurysm formation. Inspection should be carried out at relatively high magnification and we would consider reinforcing any questionable area of the arterial wall with a mattress suture if this situation were encountered again, even with no evidence of continuing bleeding. In this situation we would recommend cerebral angiography in the early postoperative period, repeated if negative, to confirm that reinforcing of the arterial wall had been successful.

False aneurysm is a potential, though apparently rare, cause of recurrent intracranial hemorrhage after successful aneurysm clipping and needs to be considered as a potential diagnosis in instances of sudden postoperative headache or unexpected neurological deterioration.

Given the difficulty of obliterating false aneurysms with preservation of the parent artery ${ }^{16}$ and the likelihood that trap- ping may be required, we would, in future, consider bypass revascularization if the false aneurysm arises from a large artery.

\section{REFERENCES}

1. Ferry DJ, Kempe LG. False aneurysm secondary to penetration of the brain through orbitofacial wounds. Report of two cases. J Neurosurg 1972; 36: 503-506.

2. Cockrill HH, Jimenez JP, Goree JA. Traumatic false aneurysm of the superior cerebellar artery simulating posterior fossa tumor. Case report. J Neurosurg 1977; 46: 377-380.

3. Meguro K, Rowed DW. Traumatic aneurysm of the posterior inferior cerebellar artery caused by fracture of the clivus. Neurosurgery 1985; 16: 666-668.

4. Sedzimir CB, Occleshaw JV, Buxton PH. False cerebral aneurysm. Case report. J Neurosurg 1968; 29: 636-639.

5. Smith DR, Kempe LG. Cerebral false aneurysm formation in closed head trauma. Case report. J Neurosurg 1970; 32: 357-359.

6. Smith KR, Bardenheier JA. Aneurysm of the pericallosal artery caused by closed cranial trauma. Case report. J Neurosurg 1968: 29: $551-554$

7. Cosgrove GR, Villemure JG, Melancon D. Traumatic intracranial aneurysm due to arterial injury at surgery. Case report. J Neurosurg 1983; 58: 291-294.

8. Alexander E, Adams JE, Davis $\mathrm{CH}$. Complications in the use of temporary intracranial aneurysm clip. J Neurosurg 1963;20: 810-811

9. Reina A, Seal RB. False cerebral aneurysm associated with metastatic carcinoma of the brain. Case report. J Neurosurg 1974; 41: 380-382.

10. Weir B, MacDonald N, Mielke B. Intracranial vascular complications of choriocarcinoma. Neurosurgery 1978; 2: 138-142.

11. Overton MC, Calvin TH. Iatrogenic cerebral cortical aneurysm. Case Report. J Neurosurg 1966; 24: 672-675.

12. Lassman LP, Ramani PS, Sengupta RP. Aneurysins of peripheral cerebral arteries due to surgical trauma. Vasc Surg 1974: 8: 1-5.

13. Taylor PE. Delayed postoperative hemorrhage from intracranial aneurysm after craniotomy for tumour. Neurology. Minneap 1961: 11: 225-231.

14. Yamaura A, Makino $H$, Hachisu $H$, et al. Secondary aneurysm due to arterial injury. Surg Neurol 1978; 10: 327-333.

15. Parkinson $D$, West $M$. Traumatic intracranial aneurysm. J Neurosurg 1980; 52: 11-20.

16. Raimondi AJ, Yashon D, Reyes C, et al. Intracranial false aneurysms. Neurochirurgia (Stuttg) 1968; 11:219-233.

17. Samson DS, Hodosh RM, Clark WK. Microsurgical evaluation of the pterional approach to aneurysms of the distal basilar circulation. Neurosurgery 1978; 3: 135-141.

18. Yasargil MG, Antic J, Laciga R, et al. Microsurgical pterional approach to aneurysms of the basilar bifurcation. Surg Neurol 1976; 6: 83-91.

19. Cressman MR, Haynes GJ. Traumatic aneurysm of the anterior choroidal artery. Case report. J Neurosurg 1966; 24: 102-104.

20. Higazi I, El-Banhawy A, El-Nady F. Importance of angiography in identifying false aneurysm of the middle meningeal artery as a cause of extradural hematoma. Case report. J Neurosurg 1969; 30: $172-176$.

21. Wortzman G, Tucker WS, Gershater R. Traumatic aneurysm in the posterior fossa. Surg Neurol 1980; 13: 329-332.

22. White JC, Sayre GP, Whisnant JP. Experimental destruction of the media for the production of intracranial aneurysms. J Neurosurg 1961; 18: 741-745.

23. Drake CG. Subdural hematoma from arterial rupture. J Neurosurg 1961; 18: 597-601.

24. Krendel DA, Ditter SM, Frankel MR, et al. Biopsy-proven cerebral vasculitis associated with cocaine abuse. Stroke 1990;21: 1648. 